\title{
The effects of a TMS double lesion to a cortical network
}

\author{
Ian G.M. Cameron ${ }^{1}$, Andreea Cretu ${ }^{2}$, Femke Struik $^{3}$, Ivan Toni ${ }^{1}$ \\ ${ }^{1}$ Donders Institute for Brain Cognition and Behaviour, Centre for Cognitive Neuroimaging, \\ Radboud University Nijmegen, the Netherlands \\ ${ }^{2}$ Department of Health Sciences and Technology, ETH Zürich, Zürich Switzerland \\ ${ }^{3}$ Radboud University Medical Centre, Department of Psychiatry, Nijmegen, the Netherlands
}

\begin{abstract}
Transcranial magnetic stimulation (TMS) is often used to understand the function of individual brain regions, but this ignores the fact that TMS may affect network-level rather than nodal-level processes. We examine the effects from a "double lesion" to two frontoparietal network nodes compared to the effects from single lesions to either node. We hypothesize that the absence of additive effects indicates that a single lesion is consequential to a network-level process. Twenty-three humans performed pro- (look towards) and anti- (look away) saccades after receiving continuous theta-burst stimulation (cTBS) to right frontal eye fields (FEF), dorsolateral prefrontal cortex (DLPFC) or somatosensory cortex (S1) (the control region). On a subset of trials, a TMS pulse was applied to right posterior parietal cortex (PPC). FEF, DLPFC and PPC are important frontoparietal network nodes for controlling anti-saccades. Bayesian Ttests were used to test hypotheses for additive double lesion effects on saccade behaviors (cTBS plus TMS pulse) against the null hypothesis that double lesion effects are not different than single lesion effects. We observed strong evidence $\left(\mathrm{BF}_{10}=325.22\right)$ that DLPFC cTBS plus PPC TMS lesion enhanced impairments in ipsilateral anti-saccade amplitudes over DLPFC cTBS alone, but not over the effect of the PPC pulse alone $\left(\mathrm{BF}_{10}=0.75\right)$. Therefore, effects were not additive, and no other evidence for additive effects was found $\left(\mathrm{BF}_{10}<3\right)$. This suggests that saccade-control computations are distributed across this network, with some degree of compensation by PPC for the DLPFC lesion.
\end{abstract}

Keywords: Transcranial magnetic stimulation, Prefrontal cortex, FEF, Frontal Eye Fields, Parietal Cortex, Saccade 


\section{Introduction}

It is well known that the effects of transcranial magnetic stimulation (TMS) extend beyond the site of stimulation (Ilmoniemi et al., 1997; Ko et al., 2008; Morishima et al., 2009; Paus et al., 1997; Ruff et al., 2006). In some instances, distal effects may reflect compensatory responses to the TMS lesion (Hartwigsen et al., 2013; O’Shea, Johansen-Berg, Trief, Göbel, \& Rushworth, 2007; Sack, Camprodon, Pascual-Leone, \& Goebel, 2005), suggesting "homeostatic metaplasticity" (Müller-Dahlhaus \& Ziemann, 2015) at the level of a network node. Here we assess another functionally relevant possibility: whether behavioral consequences of a spatiallylocalized perturbation from TMS are driven by the distributed nature of computations throughout a circuit (Price \& Friston, 2002).

The saccadic eye-movement system provides a testing ground for assessing circuit-level consequences of TMS (Leigh \& Kennard, 2004; Munoz, Armstrong, \& Coe, 2007). Roles of three cortical nodes, frontal eye fields (FEF), dorsolateral prefrontal cortex (DLPFC), and posterior parietal cortex (PPC) have been well-described (Johnston \& Everling, 2011; Munoz \& Everling, 2004; Paré \& Dorris, 2011). In the anti-saccade task (where subjects must look away from a peripheral visual stimulus (Hallett, 1978)) DLPFC is thought to be critical to establishing the appropriate task set and preventing an automatic saccade to the stimulus; FEF is thought to be critical to voluntary saccade programming, and to "preparatory set"; and FEF, along with PPC are thought to be critical to the visuo-motor transformations to develop a saccade "vector" to the opposite direction of a stimulus (Connolly, Goodale, Menon, \& Munoz, 2002; Leigh \& Kennard, 2004; Munoz \& Everling, 2004).

Evidence shows how DLPFC, FEF and PPC interact as part of a distributed system. For instance, TMS to either DLPFC, FEF (or supplementary eye fields) during saccade programming 
prolonged reaction times, suggesting that "preparatory set" was distributed between all three nodes (Nagel et al., 2008). Magnetoencephalography (MEG) and fMRI showed that FEF and PPC are both involved in the attentional aspects of the anti-saccade "vector" (Medendorp, Goltz, \& Vilis, 2005; Moon et al., 2007), and TMS to FEF or PPC produces hypometric anti-saccades (Cameron, Riddle, \& D’Esposito, 2015; Jaun-Frutiger, Cazzoli, Müri, Bassetti, \& Nyffeler, 2013; Nyffeler, Hartmann, Hess, \& Müri, 2008). However, it is not possible to distinguish a difference in timing (even with MEG) between when an anti-saccade program is developed in the PPC compared to FEF (Moon et al., 2007) implying a distributed process.

We build on this knowledge to study the effects on behavior after a "double lesion" to this network in the right hemisphere. Shortly after applying continuous theta-burst stimulation (Huang, Edwards, Rounis, Bhatia, \& Rothwell, 2005) to either right FEF or DLPFC, we measure the consequences of a second time-resolved perturbation to the circuit, in the form of a single TMS pulse to right PPC. This approach arbitrates between five hypotheses regarding consequences of the double lesion. In hypothesis A - "Additive", the double lesion could produce an additive effect by concurrently impairing spatially separate nodes that provide critical, but computationally distinct functions, resulting in behavioral perturbations that are greater than the effect of either perturbation alone (Figure 1A). Alternatively, hypothesis B - "Distributed" pertains to the case where computations are performed by a distributed system at the networklevel, so a single lesion to either node should perturb behavior as much as the double lesion (Price, Hope, \& Seghier, 2017) (Figure 1B). In hypothesis C - “Compensatory” - distal nodes could compensate for the perturbation, which would predict greater effects from the double lesion compared to the cTBS lesion alone (Figure 1C), because the second lesion impairs a region that has become more important functionally because of the first (cTBS) lesion. In 
hypothesis D - "Spreading" the effects from cTBS spread trans-synaptically to other portions of the network (Ko et al., 2008), predicting greater effects from the double lesion than to the single pulse lesion alone (Figure 1D). Finally, in “Boosting”, additional regions in the network could provide homeostatic compensation, which would manifest as a perplexing boost to performance following cTBS (alone), and which could reduce or prevent the impairment from additional TMS perturbations (Figure 1E). (The difference between this and the Compensatory hypothesis, is that there is the perplexing boost to performance after cTBS).

To discriminate between those hypotheses, we first used functional magnetic resonance imagining (fMRI) to localize right DLPFC, FEF and PPC in individual human subjects performing an anti-saccade task. These regions were then used for targeting subject-specific TMS interventions while participants performed the same task outside the scanner. Performance (percentage correct direction), reaction times, and saccade amplitudes were assessed using Bayesian t-tests, useful to provide statistical evidence in favor or against enhanced effects from the double- compared to single-TMS lesions.

Figure 1: Hypotheses for the effects of TMS "lesions" to two oculomotor network nodes (e.g., F: frontal eye fields / D, dorsolateral prefrontal cortex; and P, posterior parietal cortex) in the same hemisphere. A) "Additive": additive impairment from a double lesion compared to a single lesion to either node. B) "Distributed": no additive effects (a single lesion to the network is disruptive). C) "Compensatory": compensatory effect from second node that became more important. D) "Spreading": enhanced effect due to cTBS spreading through the network to influence the second node. E) "Boosting": additional network regions (region 'Z') provide sources of compensation after cTBS leading to a boost to performance. 
Single Lesions

A

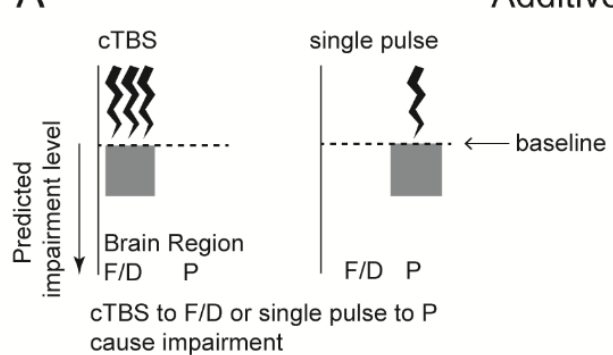

B

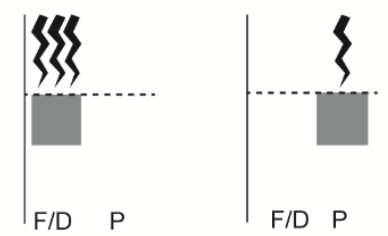

CTBS to F/D or single pulse to $P$ cause impairment
Additive Effect

\section{Double Lesions}

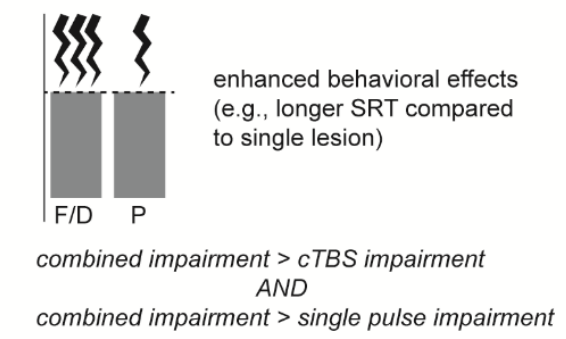

Distributed Effect

C

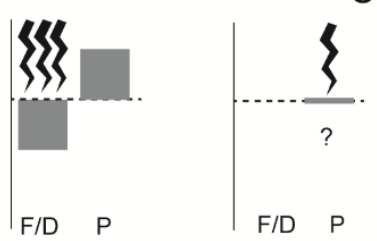

$P$ compensates for cTBS effect on F/D (TMS to P may not necessarily cause impairment, if $\mathrm{P}$ is not normally as important)

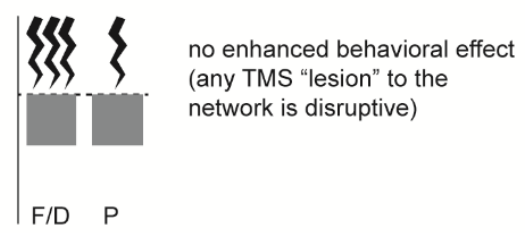

combined impairment $=c$ TBS impairment AND

combined impairment $=$ single pulse impairment

D

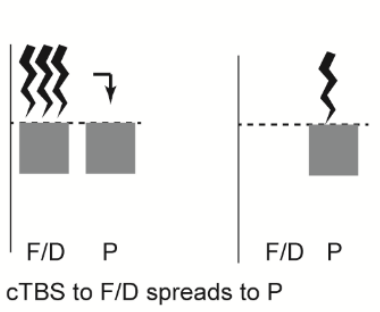

\section{Spreading Effect}

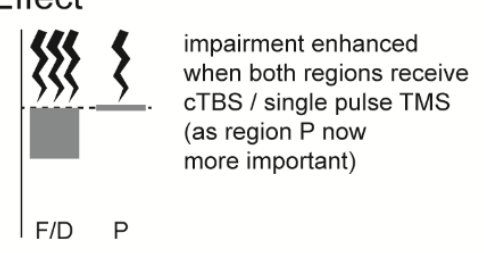

combined impairment > cTBS impairment

Compensatory Effect 


\section{Materials and methods}

\section{Participants}

The study was approved by the local ethics committee (Commissie Mensgebonden Onderzoek, Arnhem-Nijmegen) and written informed consent was obtained from the participants in accordance with the Declaration of Helsinki. A total of 27 healthy right-handed, young-adult, human subjects were recruited for 4 sessions approximately 1 week apart. 3 subjects were excluded for failure to provide useable eye-tracking data on all TMS sessions, and one subject had error rates on anti-saccade trials exceeding $90 \%$ (greater than 3 times the standard deviation), so was excluded resulting in a sample size of 24 participants (mean \pm SE, age $23 \pm 2$ years, 11 male).

\section{Detailed procedure}

Session 1

Participants were screened for contraindications related to fMRI, and to single-pulse TMS and cTBS according to common safety guidelines (Oberman, Edwards, Eldaief, \& PascualLeone, 2011; Rossi, Hallett, Rossini, \& Pascual-Leone, 2009). Resting and active motor thresholds were established for the first dorsal interosseous (FDI) muscle of the subject's righthand using electromyography (EMG). TMS was applied using a hand-held bi-phasic figure-eight coil with a $75 \mathrm{~mm}$ outer winding diameter (MagVenture, Denmark), connected to a MagProX100 system (MagVenture). Coil orientation was chosen to induce a posterior-anterior electrical field in the brain ( $45^{\circ}$ from the mid-sagittal axis).

Subjects performed 5 runs of an interleaved pro-(look towards)/anti-(look away) saccade task to identify the cortical regions of interest (Figure 2B). An interleaved task was utilized as evidence suggests an important role for DLPFC (Everling \& DeSouza, 2005; Johnston, Koval, 
Lomber, \& Everling, 2014) as well as for FEF (DeSouza, Menon, \& Everling, 2003) in task or "preparatory set" and thus could not simply default to an anti-saccade task set on each trial. Two target positions $\left(13^{\circ}\right.$ or $\left.9^{\circ}\right)$ in the left and right direction were included so that subjects would have to rely on spatial information to calculate the saccade vector. In this way, we could be sure that the paradigm required DLPFC, FEF and PPC processes.

\section{Detailed fMRI procedure}

Functional MRI scans were obtained with a 3 Tesla MRI scanner (Skyra, Siemens Medical Systems Erlangen, Germany) using a 32-channel head coil. The functional images were acquired with multiband sequence (acceleration factor $=3$, repetition time $(\mathrm{TR})=1000 \mathrm{~ms}$, echo time $(\mathrm{TE})=30 \mathrm{~ms}$, flip angle $\left.=60^{\circ}\right)$. Each volume consisted of 33 slices, with a distance of $17 \%$ and a thickness of $3 \mathrm{~mm}$. The voxel resolution was $3.5 \times 3.5 \times 3.0 \mathrm{~mm}$, FoV in the read direction of $224 \mathrm{~mm}$ and FoV in the phase direction of $100 \%$. Two volumes were discarded from each functional run, to account for scanner steady state equilibrium, leading to a total of 339 volumes per run. The anatomical images were acquired with a MPRAGE sequence (repetition time (TR) $=2300 \mathrm{~ms}$, echo time $(\mathrm{TE})=3.9 \mathrm{~ms}$, voxel size $=1 \times 1 \times 1 \mathrm{~mm})$. In total, 192 images were obtained for each participant. During the scan, participants lay in a supine position and their head was stabilized using soft cushions.

Imaging data were analyzed with SPM8 (Wellcome Trust Centre for Cognitive Neuroimaging, London, UK). At the single-subject level, the data were realigned to the first volume of each run using six rigid body transformations ( 3 translations and 3 rotations). The images were then coregistered to the individual structural T1 and spatial smoothing was performed by means of an 8-mm full-width half-maximum (FWHM) Gaussian kernel. A firstlevel analysis was performed by specifying a general linear model with regressors for each 
condition (fixation trials were not modeled however). Motion parameters ( 3 translations, 3 rotations) were included as nuisance regressors.

A contrast of anti-saccade trials against baseline was computed to define $5 \mathrm{~mm}$ ROIs centered on locations of peak activation on each subject anatomical scan, using a t-contrast at $\mathrm{P}<$ 0.001 (uncorrected). Table 1 provides the Montreal Neurological Institute (MNI) coordinates of these ROIs, and their distances to the scalp as derived from Localite TMS Navigation software 2.2 (Localite, Germany). Figure 2A illustrates the coordinates on a canonical T1 scan. Right DLPFC (r-DLPFC) was defined as peak fMRI anti-saccade activity surrounding the middle frontal gyrus, anterior to the ventricles. Right FEF was defined as peak activity in the precentral sulcus (selecting medial peaks if lateral peaks were also present, to relate more to anti-saccade processes (Neggers et al., 2012)). Right PPC was defined as peak activity in the intraparietal sulcus, selecting peaks in more medial clusters if more than one was present. Finally, right S1 (the control region) was localized anatomically for each participant, as the most superior extent of the postcentral gyrus, located on average $9 \pm 2 \mathrm{~mm}$ lateral to the longitudinal fissure to avoid lateral proprioceptive eye-position signals (Balslev, Albert, \& Miall, 2011; Zhang, Wang, \& Goldberg, 2008) (Table 1, Figure 2A).

Table 1: Regions Of Interest (ROI) information (average \pm standard deviations (mm))

\begin{tabular}{lcccc} 
& \multicolumn{2}{c}{ Coordinates (MNI space) } & Distance to scalp \\
& $\mathbf{X}$ & $\mathbf{Y}$ & $\mathbf{Z}$ & \\
\hline r-DLPFC & $35 \pm 7$ & $45 \pm 10$ & $31 \pm 7$ & $19 \pm 4$ \\
r-FEF & $30 \pm 5$ & $-5 \pm 4$ & $57 \pm 6$ & $26 \pm 5$ \\
r-PPC & $20 \pm 7$ & $-66 \pm 6$ & $60 \pm 5$ & $22 \pm 4$ \\
r-S1 & $9 \pm 2$ & $-38 \pm 5$ & $79 \pm 2$ & $20 \pm 3$
\end{tabular}


bioRxiv preprint doi: https://doi.org/10.1101/517128; this version posted April 23, 2019. The copyright holder for this preprint (which was not certified by peer review) is the author/funder. All rights reserved. No reuse allowed without permission.

A

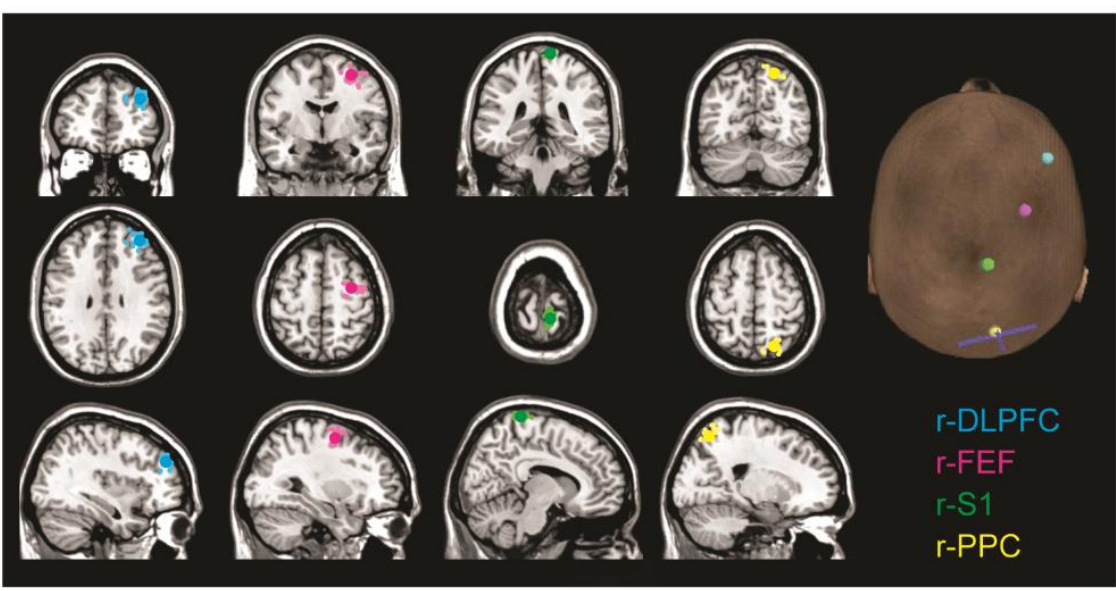

B

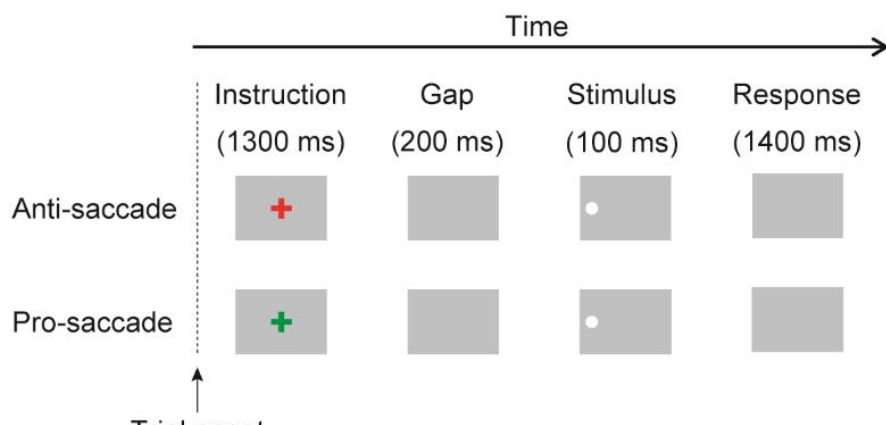

C

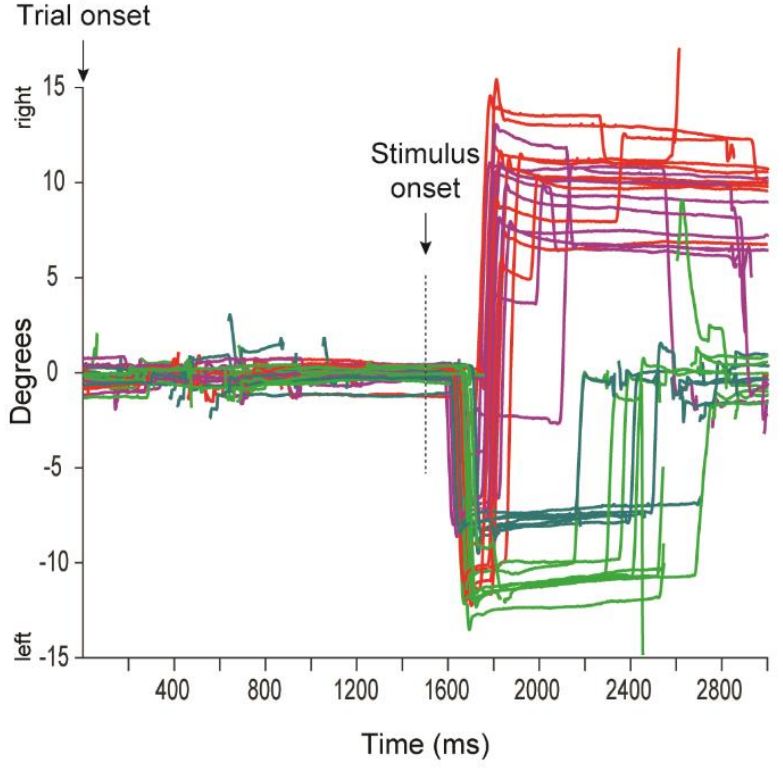

Figure 2 
Figure 2: A) MRI images: illustration of coil placement over right dorsolateral prefrontal cortex (r-DLPFC), right frontal eye fields (r-FEF), right primary sensory cortex ( $\mathrm{r}-\mathrm{S} 1)$, and right posterior parietal cortex (r-PPC) on an SPM single-subject anatomical template.

Mean coordinates are shown as large bright dots, and individual subject coordinates are shown as faint dots. Right: scalp "entry" points for TMS stimulation for a representative subject, showing also a representation of the coil orientation over right PPC (handle of coil = base of ' $T$ ' shape). B) Paradigm and stimulus timings shown for representative antisaccade and pro-saccade trials, where the target stimulus was on the left side. C) Illustrations of raw eye-traces from a representative subject in one run (subject 22841) with respect to stimuli on the left side. For $13^{\circ}$ stimuli, red illustrates anti-saccades and green illustrates pro-saccades; for $9^{\circ}$ stimuli, magenta illustrates anti-saccades, and turquoise illustrates pro-saccades. This subject made a high proportion of direction errors on anti-saccade trials in this run, indicated by the reversals of direction. Blinks are shown as gaps in the traces.

\section{Session 2-4}

cTBS was applied to r-DLPFC, r-FEF or r-S1 prior to performing the task on three separate sessions, counterbalanced for order. cTBS was applied to FEF or to DLPFC because we wished to assess double lesion effects across two nodes which are both linked to PPC, but where one (FEF) is thought to have a more direct link in visuo-motor processes (Leigh \& Kennard, 2004; Munoz \& Everling, 2004) and in network interactions described in the resting state (Corbetta, Kincade, Lewis, Snyder, \& Sapir, 2005; He et al., 2007; Vossel, Geng, \& Fink, 2014). cTBS was delivered with a posterior-anterior direction of the electric field induced in the brain, with the handle pointed backwards at approximately $30^{\circ}$ to the sagittal plane. In this way the outer windings of the TMS coil did not overlap the other ROIs. TMS coil alignment was achieved using Localite and a subject-specific anatomical scan.

The parameters for cTBS were identical to those described by Huang and colleagues (2005) consisting of $50 \mathrm{~Hz}$ triplets repeated at $5 \mathrm{~Hz}$ over a period of $40 \mathrm{~s}$ (Huang et al., 2005). Stimulation intensity for cTBS was defined as $80 \%$ of the active motor threshold (AMT), defined as peak-to-peak MEP amplitudes exceeding $200 \mu \mathrm{V}$ on 5 out of 10 trials, while subjects 
maintained voluntary contraction of approximately $10 \%$. Stimulation intensity for single pulse TMS to PPC was set at $110 \%$ of the resting motor threshold (RMT), defined as peak-to-peak MEP amplitudes of $50 \mu \mathrm{V}$ on 5 of 10 trials. 40 s of cTBS (at $80 \%$ of active motor threshold) has effects lasting approximately 50 minutes (Wischnewski \& Schutter, 2015), providing sufficient time to test the influence of the PPC pulse.

\section{Eye Tracking and Task}

The position of the right eye was recorded using an infrared Eyelink 1000 eye tracker

(SR Research, Ottawa, Canada) with a $1000 \mathrm{~Hz}$ sampling rate. A 9- point calibration was carried out and a drift correction point was used as the inter-trial fixation point. Saccades were identified by a horizontal deflection ( $3 \mathrm{X}$ standard deviations of the baseline velocity) and duration between 15 and $150 \mathrm{~ms}$. The camera was positioned under the stimulus screen, approximately 60 $\mathrm{cm}$ away from the eyes of the participant, who sat precisely at $70 \mathrm{~cm}$ from a wide-angle LCD screen (with central presentation zone set at 4:3, $1024 \times 768$ resolution).

Subjects performed the same task (Figure 2B) as in the fMRI. Representative eye-traces from a single subject is shown in Figure 2C. In each run, there were 72 trials, of which 48 contained a TMS pulse presented to PPC at a random interval between 30 and $300 \mathrm{~ms}$ after onset of the peripheral stimulus (described in Data Analysis). The first run commenced 10 minutes after cTBS, and was analyzed up to 50 minutes after cTBS to capture the same cTBS effects on each session. Subjects were asked to perform 5 runs, each taking approximately 8 minutes including drift corrections and breaks, meaning that for each condition of interest (task, direction) there were 30 trials without the single pulse ("pulse absent"), and 60 trials containing the single pulse. 


\section{Data analysis}

Data was analyzed with custom MATLAB v11 programs (The MathWorks Inc., Natick, MA). Valid trials consisting of correct and incorrect directions were separated from invalid trials, consisting of saccade reaction times (SRTs) $<90 \mathrm{~ms}$ (anticipatory errors), slower than $1000 \mathrm{ms,}$ and trials where the TMS pulse to PPC occurred after saccade onset. Three behavioral parameters of interest were analyzed: amplitude of the primary saccade, percentage correct direction, and saccade reaction time (SRT).

We first set a division between an "Early" and "Late" pulse time bin as follows: using the pulse absent trials, we collected the SRTs across subjects for correctly performed anti-saccades, and for direction errors on anti-saccades for each cTBS session separately, and plotted these data in $10 \mathrm{~ms}$ bin histograms (Figure 3). A binomial test revealed the first bin (black arrows, Figure 3) where the two trial types were no longer significantly different than chance (50\%); these bins occurred at $150 \mathrm{~ms}$ for the S1 cTBS and DLPFC cTBS sessions, and at $160 \mathrm{~ms}$ for the FEFcTBS session. This method approximates the division between visually triggered "express" prosaccades, and voluntary saccades (Munoz \& Everling, 2004), and is important to approximate when the PPC pulse would have greater influences during visual processing rather than motor programming components of an anti-saccade, which are in different directions. 

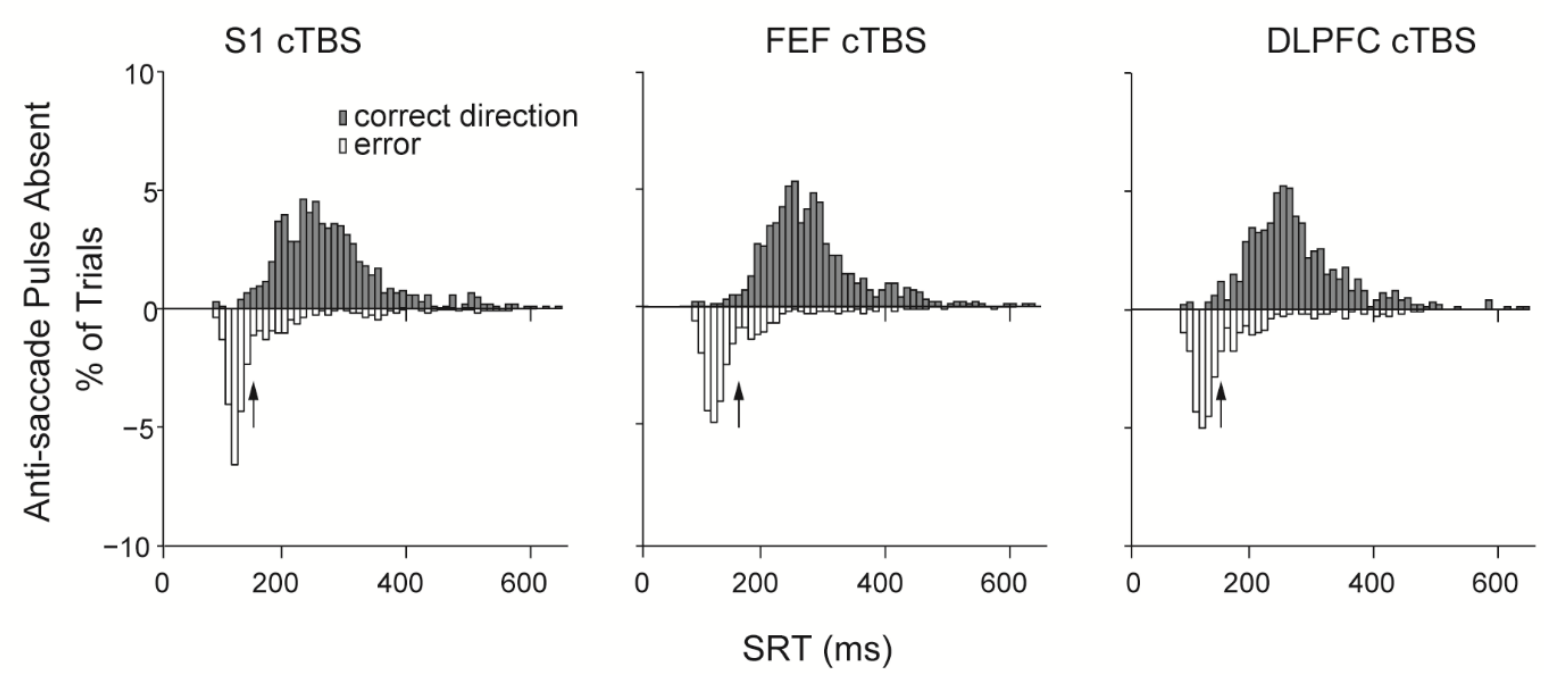

Figure 3: Derivation of the Early and Late PPC pulse bins based on anti-saccade reaction times. Reaction time distributions were calculated for correct and direction error antisaccades in PPC Pulse Absent trials on each cTBS session. A binomial sign test was performed compared the distributions, and arrows indicate the first reaction time bin where the two distributions were no longer significantly different. This value was taken as the boundary for Early and Late PPC pulses.

Next, we performed a repeated measures ANOVA using pulse absent trials to determine if there were significant interactions between the site of cTBS and stimulus eccentricity for amplitudes. However, no interactions with cTBS Site and Eccentricity were significant, $F(2,44)$ $<1.75, P>0.19$, so we collapsed across eccentricity.

To directly assess our five network hypotheses regarding the combined effects from cTBS and the PPC pulse (Figure 1), we performed Bayesian paired-sample t-tests in JASP (JASP Team, 2017) (Figures 4-7, brackets). A Bayes Factor $\left(\mathrm{BF}_{10}\right)$ indicates the evidence for the alternative hypothesis relative to the null hypothesis given the data. Our tests were focused first on situations where the "double lesion" produces impairments that were greater than the single lesions; thus, the Bayes Factor $\left(\mathrm{BF}_{10}\right)$ here indicates whether the combined effects were greater than the individual effects from cTBS alone, or from PPC TMS alone). For amplitude and 
percent correct, lower values are indicative of greater impairments: therefore, the alternative hypothesis for $\mathrm{BF}_{10}$ is that the difference of the combined effect minus the single lesion effect was less than 0 , and the null hypothesis would be that this difference is not less than zero. For reaction times, higher values are indicative of an impairment (slower latency), so the alternative hypothesis is that the combined effect minus the single lesion effect is greater than zero (and the null hypothesis is that it is not greater than zero). Note, however, that strong evidence from these tests for the null hypothesis (not less than zero) could be driven by a difference in the opposite direction. When such "strong” evidence was found $\left(\mathrm{BF}_{10}<0.1\right)($ Jeffreys, 1961; Wetzels et al., 2011), we subsequently performed tests in the opposite direction to determine if the effect of the single lesion was greater than that of the double lesion.

We report evidence for behavioral impairments that meet or exceed "substantial" $\left(\mathrm{BF}_{10}>\right.$ 3) (Jeffreys, 1961; Wetzels et al., 2011). Between 0.33 and 3, the evidence is considered only "anecdotal", and in relation to P-values, it was shown that approximately $70 \%$ of "positive" results from 855 tests falling in the interval between $P<0.01$ to $P<0.05$ corresponded to only “anecdotal" evidence (Wetzels et al., 2011). Therefore, our boundary criteria of "substantial" is conservative in relation to typical P-values.

Tests for each individual trial type compared to the control condition (S1 cTBS, PPC Pulse Absent) were also conducted using Bayesian one-sample t-tests in JASP to confirm if the individual lesions themselves caused impairments. Here, the $\mathrm{BF}_{10}$ indicates the relative likelihood that cTBS or single pulse TMS impaired behavior compared to the null hypothesis that the effects were equal to the control condition. The values for these tests are listed in Tables 2-5, and are illustrated as asterisks in Figure 4-7 when substantial. 


\section{Results and Discussion}

\section{FEF cTBS vs control cTBS conditions: anti-saccades}

Saccade amplitude

There was substantial evidence that FEF cTBS caused impairments in leftward antisaccade amplitudes for conditions also involving PPC pulses, and for rightwards anti-saccades for conditions involving the late PPC pulse (Table $2 \mathrm{~A}, \mathrm{BF}_{10}>3$ ). There was not substantial evidence that the PPC pulse on its own produced an impairment, and there was also not substantial evidence (Figure 4A, brackets, all $\mathrm{BF}_{10} \leq 2.91$ ) to indicate enhanced impairments from the double lesion condition compared to either single lesion condition.

Table 2: Bayes Factors for the alternative (impairment) vs. null (no impairment) hypothesis $\left.\mathrm{BF}_{10}\right)$ for left and right anti-saccade trials relative to control cTBS

\begin{tabular}{cccccccc}
\hline Left & cTBS & PPC & $\mathrm{BF}_{10}$ & Right & cTBS & PPC & $\mathrm{BF}_{10}$ \\
Anti & site & pulse & & Anti & site & pulse & \\
& & & & & & &
\end{tabular}

A) Amplitude

\begin{tabular}{ccccccc} 
FEF & Absent & 2.69 & & FEF & Absent & 0.26 \\
& Early & $\mathbf{4 . 0 9}$ & & & Early & 1.31 \\
& Late & $\mathbf{4 . 5 8}$ & & & Late & $\mathbf{7 . 6 0}$ \\
\cline { 2 - 3 } \cline { 5 - 6 } S1 & Early & 0.35 & & S1 & Early & 0.52 \\
& Late & 0.39 & & & Late & 1.21
\end{tabular}

\section{B) Percent Correct}

\begin{tabular}{ccccccc} 
FEF & Absent & 0.15 & & FEF & Absent & 0.16 \\
& Early & 0.06 & & & Early & 0.07 \\
& Late & 0.06 & & & Late & 0.06 \\
\cline { 1 - 2 } \cline { 5 - 6 } S1 & Early & 0.08 & & S1 & Early & 0.07 \\
& Late & 0.05 & & & Late & 0.06
\end{tabular}

\section{C) Saccade Reaction Time}

\begin{tabular}{ccccccc} 
FEF & Absent & 0.59 & & FEF & Absent & 0.29 \\
& Early & 0.23 & & & Early & 0.25 \\
& Late & 0.24 & & & Late & 0.74 \\
\cline { 2 - 3 } \cline { 5 - 7 } & Early & 0.22 & & S1 & Early & 0.45 \\
& Late & $\mathbf{1 1 4 9 . 8 0}$ & & & Late & $\mathbf{1 3 0 9 . 9 6}$ \\
\hline
\end{tabular}

Bold values: $\mathrm{BF}_{10}>3$ 


\section{Percentage correct direction}

There was not substantial evidence that anti-saccades were impaired by either form of

TMS; in fact, strong evidence towards the null hypothesis was found for conditions with the PPC

pulse (Table $2 \mathrm{~B}, \mathrm{BF}_{10}<0.1$ ). (Bayesian t-tests performed in the opposite direction revealed

substantial or greater evidence $\left(\mathrm{BF}_{10}>3\right)$ for a performance benefit from the PPC pulses).

Similarly, there was strong evidence that there were not enhanced impairments from the double

lesion compared to either single lesion (Figure 4B).

Figure 4: Effects on left and right anti-saccades when the double lesion involved FEF cTBS and PPC TMS is compared to the single lesion conditions. All data is normalized to the cTBS control condition (cTBS to S1, no PPC pulses). Error bars represent standard error of the mean across subjects $(\mathrm{N}=23)$, and dark grey represents the double lesion conditions. Values between brackets indicate the Bayes Factor evidence for the alternative hypothesis that the combined effects from the double lesion resulted in a greater impairment (more negative values, note the $\mathrm{Y}$ axis is reversed for reaction times) compared to the effects of the single lesions. Values $>3$ provide substantial evidence for the alternative hypothesis that the combined effects resulted in a greater impairment than the single lesion effects. Asterisks show the results from Bayesian one-sample t-tests for evidence that the values are $<0$ where $\mathrm{BF}_{10}>3$. 
A

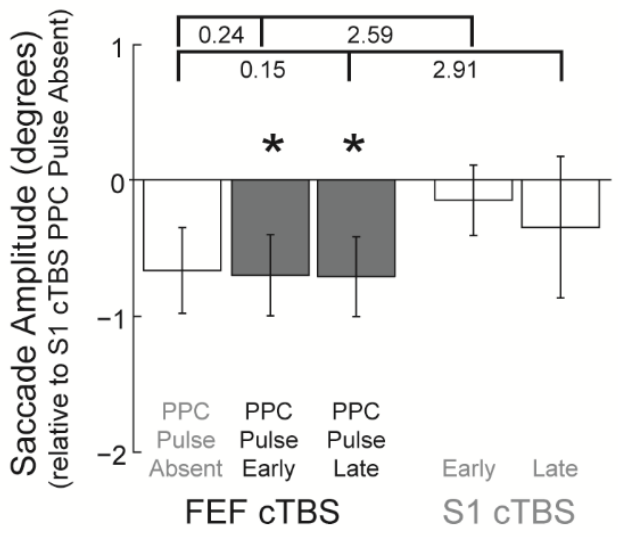

B

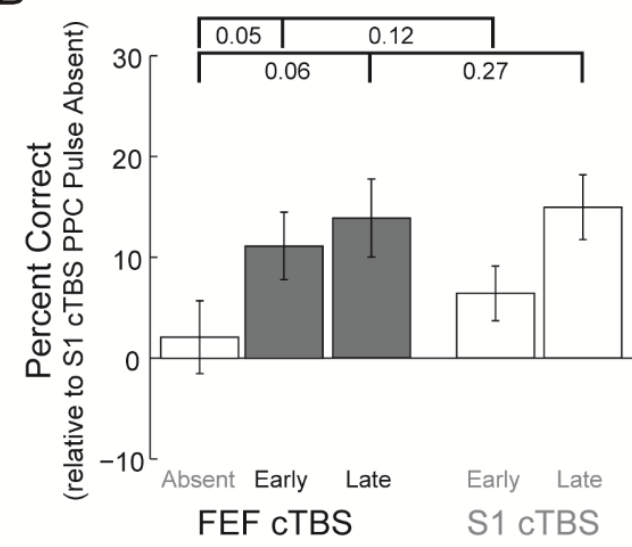

C

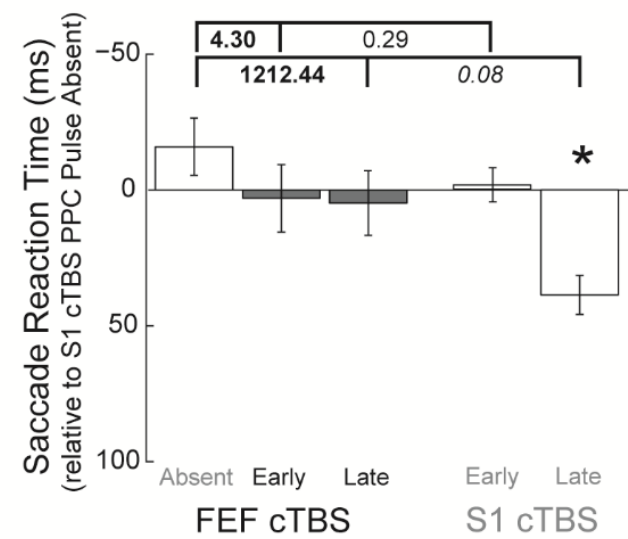

Right Anti

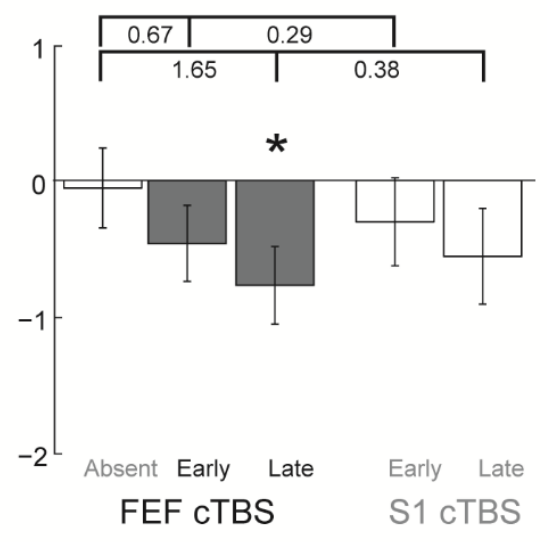

*, Bold values: $\mathrm{BF}_{10}>3$
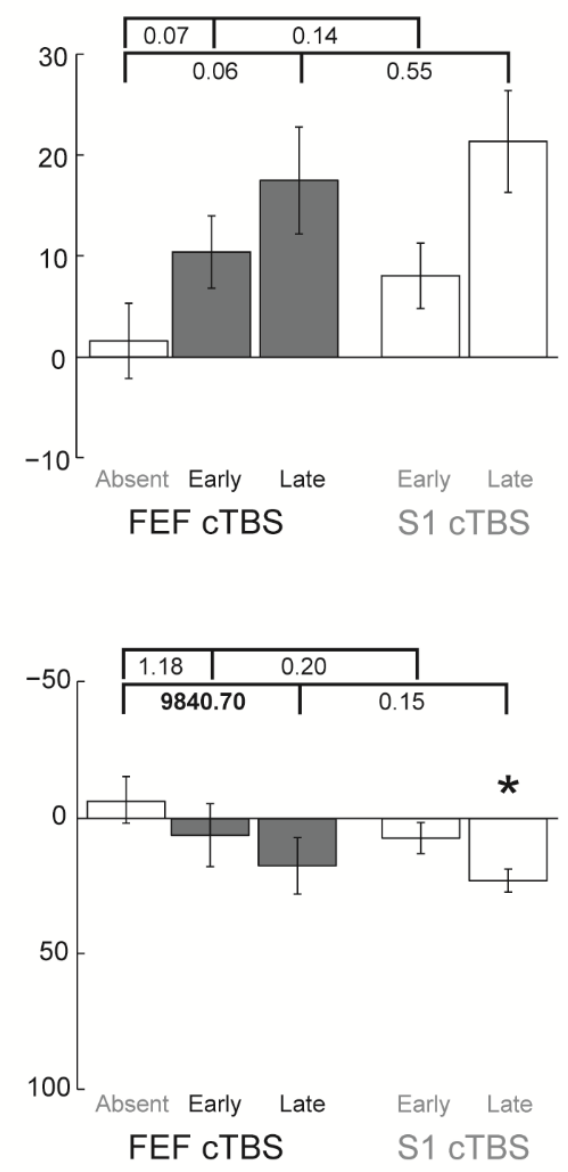

Figure 4 


\section{Saccade Reaction Times (SRT)}

For SRT, “decisive” (Wetzels et al., 2011) evidence for impairments were observed for conditions with the late PPC pulse alone, but not for those following FEF cTBS (Table 2C). Strong evidence was found that FEF cTBS plus a late PPC pulse did result in enhanced impairments relative to FEF cTBS alone (and substantial evidence was found for an enhanced impairment for the early PPC pulse for leftwards anti-saccades) (Figure 4C). However, strong evidence was found that impairments for leftwards anti-saccades were not greater when the late PPC pulse followed FEF cTBS compared to when it was alone (Figure 4C, BF $=0.08$, italicized): when tested in the reverse direction, there was substantial evidence that the impairment after the late PPC pulse alone was greater than after FEF cTBS, $\mathrm{BF}_{10}=4.12$.

\section{Interpretation}

We did not find evidence to suggest Hypothesis A (an "additive" effect) from the double lesion across any of the saccade behaviors. Substantial evidence showed impairments to antisaccade amplitude following FEF cTBS when PPC pulses were present; however, because there was not substantial evidence that PPC pulses on their own caused impairments, nor were the effects enhanced relative to those following FEF cTBS, we conclude that cTBS to FEF was consequential to anti-saccade amplitudes suggesting a "distributed" effect (Hypothesis B).

For saccade reaction times, we found evidence for enhanced impairments from the double lesion compared to FEF cTBS on its own. We do not believe this indicates compensation by PPC, because these conditions (FEF cTBS plus PPC pulse) did not reveal substantial evidence for impairment on their own. In fact, the late PPC pulses on their own produced impairments that were greater than the double lesion for contralateral anti-saccades (Hypothesis E). We conclude therefore that later PPC pulses were disruptive to the motor component of the anti-saccade. 
Following FEF cTBS however, a compensatory mechanism might be revealed by other network structures (e.g., the superior colliculus, SC) which aid in anti-saccade generation. One possibility is that after FEF cTBS, there is compensation by DLPFC-colliculus projections to contralateral SC saccade neurons (Everling \& Johnston, 2013), reducing the disruptive effect from a PPC pulse on the same network structures. This is sensible, considering the PPC pulses also produced substantial anti-saccade performance benefits, and human EEG evidence has shown that the posterior parietal/occipital cortex is involved in triggering "express" pro-saccades (Hamm, Dyckman, Ethridge, McDowell, \& Clementz, 2010), possibly by a cortical-SC mechanism (Chen, Liu, Wei, \& Zhang, 2013; Watanabe, Hirai, Marino, \& Cameron, 2010). A PPC pulse could thus disrupt the bias towards stimulus-driven saccades thus indirectly facilitating antisaccade performance.

However, these effects could also be driven by the auditory/or somatosensory influence of the pulse (Duecker, de Graaf, Jacobs, \& Sack, 2013; Duecker \& Sack, 2013), which could engage a startle-like reflex that inhibits ongoing motor commands, by acting also on the SC or brain stem saccade generator circuits (Xu-Wilson, Tian, Shadmehr, \& Zee, 2011) (perhaps with less of a consequence in cases of compensation). As the goal of this study was to compare hypotheses regarding the double vs single lesions situations, the interesting comparisons are those between the PPC pulses following control versus verum cTBS, which both have the same auditory/somatosensory influences of the PPC pulse.

\section{DLPFC cTBS vs control cTBS conditions: anti-saccades}

\section{Saccade amplitude}

There was substantial evidence for impairments to anti-saccades after DLPFC cTBS in conditions involving the late PPC pulse, and for DLPFC cTBS alone for leftward anti-saccades 
(Table 3A). Strong evidence was found for an enhanced impairment from the combined lesion effects for rightward anti-saccades after the late pulse relative to the DLPFC $\mathrm{cTBS}$ alone $\left(\mathrm{BF}_{10}=\right.$ 325.22), but this was not found compared to the effects of the late PPC pulse alone $\left(\mathrm{BF}_{10}=0.75\right)$

(Figure 5A).

Table 3: Bayes Factors for the alternative (impairment) vs. null (no impairment) hypothesis $\left.\mathrm{BF}_{10}\right)$ for left and right anti-saccade trials relative to control cTBS. (The effect of the PPC pulse relative to control cTBS is shown in duplication as in Table 3)

\begin{tabular}{cccccccc}
\hline Left & cTBS & PPC & $\mathrm{BF}_{10}$ & Right & cTBS & PPC & $\mathrm{BF}_{10}$ \\
Anti & site & pulse & & Anti & site & pulse &
\end{tabular}

A) Amplitude

\begin{tabular}{|c|c|c|c|c|c|}
\hline \multirow[t]{3}{*}{ DLPFC } & Absent & 4.21 & DLPFC & Absent & 0.33 \\
\hline & Early & 0.55 & & Early & 0.98 \\
\hline & Late & 4.84 & & Late & 8.84 \\
\hline \multirow[t]{2}{*}{$\mathrm{S} 1$} & Early & 0.35 & S1 & Early & 0.52 \\
\hline & Late & 0.39 & & Late & 1.21 \\
\hline
\end{tabular}

B) Percent Correct

\begin{tabular}{|c|c|c|c|c|c|}
\hline \multirow[t]{3}{*}{ DLPFC } & Absent & 0.27 & DLPFC & Absent & 0.16 \\
\hline & Early & 0.14 & & Early & 0.09 \\
\hline & Late & 0.05 & & Late & 0.05 \\
\hline \multirow[t]{2}{*}{ S1 } & Early & 0.08 & S1 & Early & 0.07 \\
\hline & Late & 0.05 & & Late & 0.06 \\
\hline
\end{tabular}

C) Saccade Reaction Time

\begin{tabular}{|c|c|c|c|c|c|}
\hline \multirow[t]{3}{*}{ DLPFC } & Absent & 0.24 & DLPFC & Absent & 0.40 \\
\hline & Early & 0.46 & & Early & 0.24 \\
\hline & Late & 1.30 & & Late & 16.96 \\
\hline \multirow[t]{2}{*}{$\mathrm{S} 1$} & Early & 0.22 & S1 & Early & 0.45 \\
\hline & Late & 1149.80 & & Late & 1309.96 \\
\hline
\end{tabular}

Bold values: $\mathrm{BF}_{10}>3$

Figure 5: Effects on left and right anti-saccades when the double lesion involving DLPFC cTBS and PPC TMS is compared to the single lesion conditions. PPC pulse conditions relative to S1 cTBS are shown in duplication as in Figure 4, and conventions are as in Figure 4. 
A

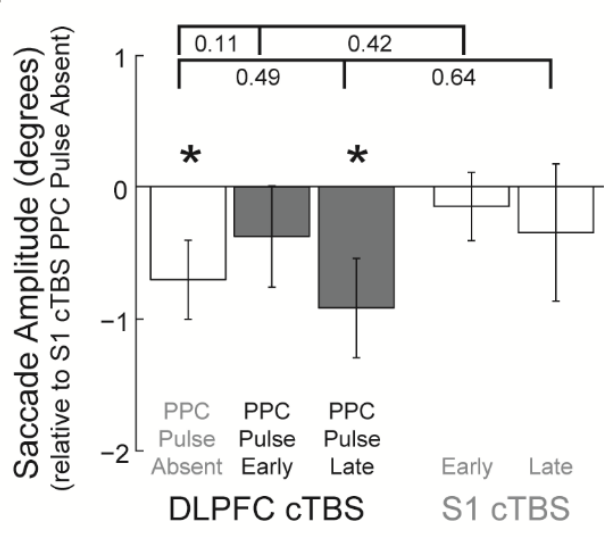

B

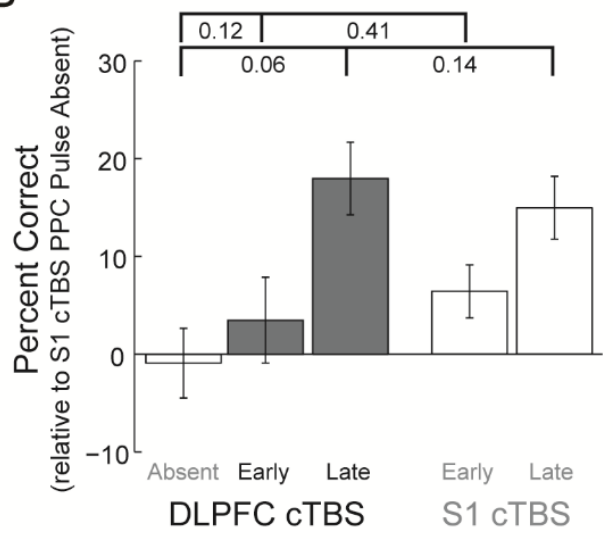

C

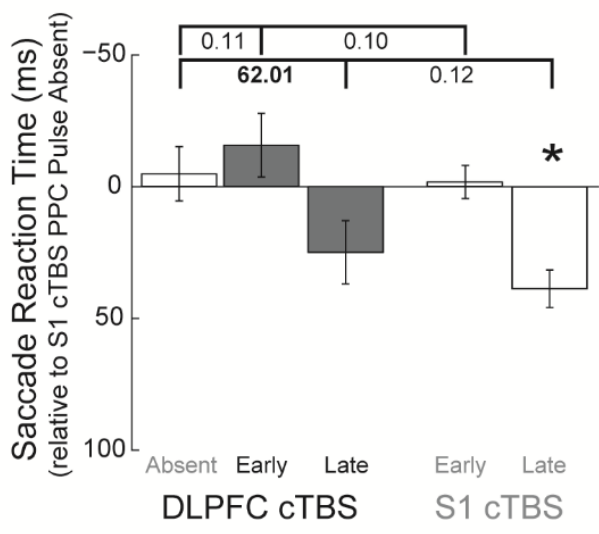

Right Anti
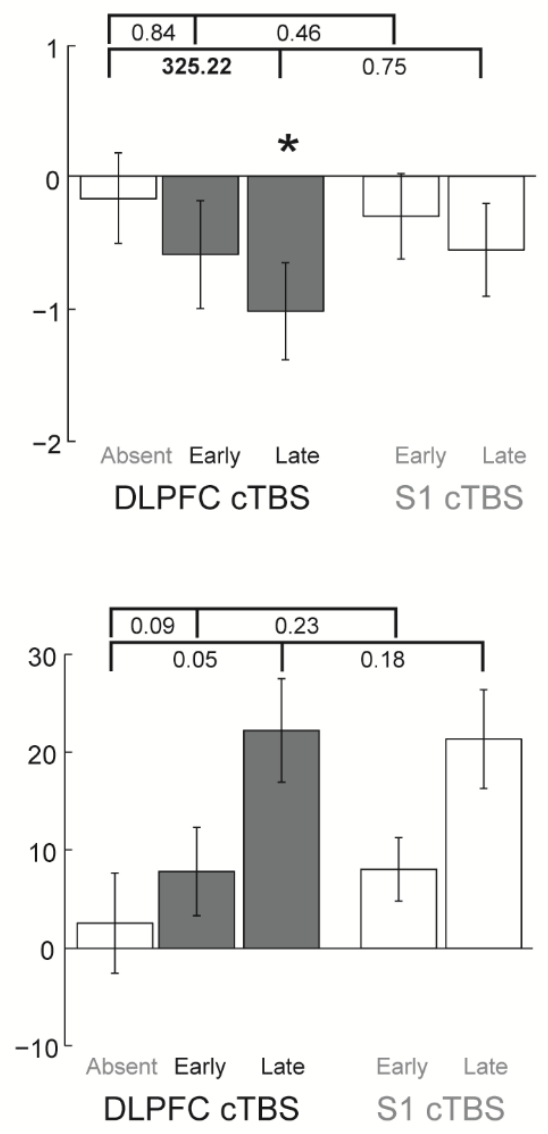

*, Bold values: $\mathrm{BF}_{10}>3$

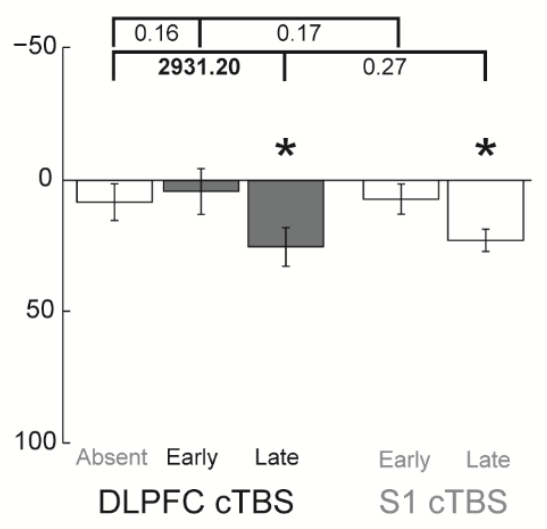

Figure 5 


\section{Percentage correct direction}

There was no evidence that anti-saccades were impaired by DLPFC cTBS, with, or without, the PPC pulse (Table 3B). (Bayesian t-tests revealed strong evidence for anti-saccade benefits to performance following DLPFC cTBS and late PPC pulses). There was also no evidence for enhanced impairment from a double compared to single lesion (Figure 5B).

\section{Saccade Reaction Times (SRT)}

There was strong evidence for impaired reaction times at the late pulse time following DLPFC cTBS for right anti-saccades (Table 3C), and there was strong evidence that the combined effects of DLPFC cTBS and a late PPC pulse resulted in enhanced impairments relative to DLPFC cTBS alone (Figure 5C), but there was no evidence for greater impairment in comparison to the PPC pulse.

\section{Interpretation}

We found strong evidence for compensation by PPC (Hypothesis C) following DLPFC cTBS for ipsilateral (rightward) anti-saccade amplitudes, but not substantial evidence for an additive effect (Hypothesis A). Importantly, there was not substantial evidence that the PPC pulses alone produced an impairment. This is consistent with a compensatory hypothesis, in that the second lesion impairs a node which has as a greater contribution (Hartwigsen et al., 2016; Sack et al., 2005). We note that these effects were lateralized, as compensation was only seen in this ipsilateral direction. cTBS to DLPFC alone produced impairments in the contralateral direction, suggesting that DLPFC lesions were more consequential for contralateral antisaccades.

In a previous study, we did not find significant impairments in saccade amplitudes following (left) DLPFC cTBS (Cameron et al., 2015), and it has also been concluded by one 
lesion study that DLPFC was not necessary for performing the spatial calculations in a memoryguided saccade task (Mackey, Devinsky, Doyle, Meager, \& Curtis, 2016). However, another study did show DLPFC lesions resulted in higher variability in memory-guided saccade endpoints, with non-significant reductions in amplitudes (Pierrot-Deseilligny et al., 2003). Such mixed findings lend support to a hypothesis that the spatial calculations for anti-saccades are performed by a distributed process. We can only speculate that compensation occurs in some circumstances depending on the particular task.

As with FEF cTBS, there was no evidence that any of the conditions impaired percentage correct direction, but there was evidence for enhanced SRT impairments from the combined double lesion compared to DLPFC cTBS alone. As addressed previously, the late PPC pulse impaired SRT on its own, suggesting the effects are more related to that of the PPC pulse.

\section{FEF cTBS vs control cTBS conditions: pro-saccades}

\section{Saccade amplitude}

Table 4A and Figure 6A show that there was not substantial evidence for effects of either TMS condition on pro-saccade amplitudes.

\section{Percentage correct direction}

Substantial impairments were found for rightwards pro-saccades following FEF cTBS during trials with the addition of a late PPC pulse (Table $\left.4 \mathrm{~B} ; \mathrm{BF}_{10}=4.53\right)$. There was also substantial evidence that the impairments to leftwards pro-saccades were greater following FEF cTBS when there was a late PPC pulse (Figure $6 \mathrm{~B} ; \mathrm{BF}_{10}=3.74$ ) compared to FEF cTBS alone. There was not substantial evidence for other impairments. 
Table 4: Bayes Factors for the alternative (impairment) vs. null (no impairment) hypothesis $\underline{\left(\mathrm{BF}_{10}\right) \text { for left and right pro-saccade trials relative to control cTBS }}$

$\begin{array}{lccccccc}\text { Left } & \text { cTBS } & \text { PPC } & \mathrm{BF}_{10} & \text { Right } & \text { cTBS } & \text { PPC } & \mathrm{BF}_{10} \\ \text { Pro } & \text { site } & \text { pulse } & & \text { Pro } & \text { site } & \text { pulse } & \end{array}$

\section{A) Amplitude}

\begin{tabular}{|c|c|c|c|c|c|}
\hline \multirow[t]{3}{*}{ FEF } & Absent & 0.61 & FEF & Absent & 0.54 \\
\hline & Early & 0.31 & & Early & 0.56 \\
\hline & Late & 0.87 & & Late & 0.30 \\
\hline \multirow[t]{2}{*}{ S1 } & Early & 0.11 & S1 & Early & 1.07 \\
\hline & Late & 0.30 & & Late & 2.32 \\
\hline
\end{tabular}

\section{B) Percent Correct}

\begin{tabular}{|c|c|c|c|c|c|}
\hline \multirow[t]{3}{*}{$\mathrm{FEF}$} & Absent & 0.12 & FEF & Absent & 1.16 \\
\hline & Early & 0.41 & & Early & 0.22 \\
\hline & Late & 2.63 & & Late & 4.53 \\
\hline \multirow[t]{2}{*}{ S1 } & Early & 0.48 & S1 & Early & 0.24 \\
\hline & Late & 1.44 & & Late & 1.19 \\
\hline
\end{tabular}

\section{C) Saccade Reaction Time}

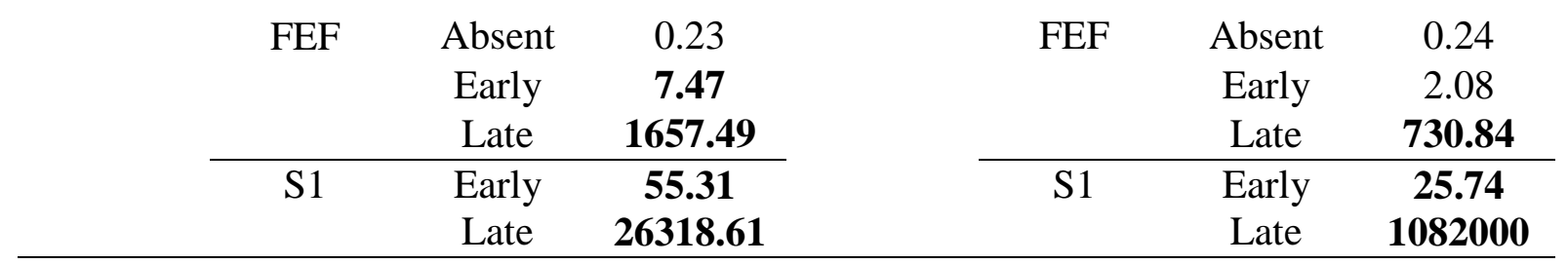

Bold values: $\mathrm{BF}_{10}>3$

Figure 6: Effects on left and right pro-saccades when the double lesion involving FEF cTBS and PPC TMS is compared to the single lesion conditions. Conventions as in Figure 4. 
A

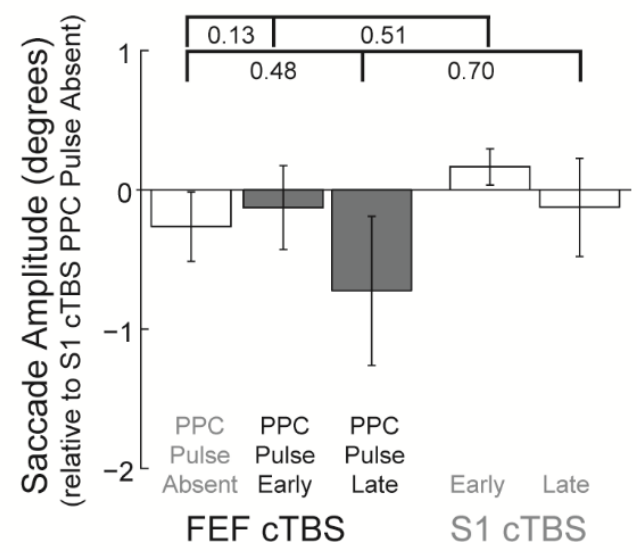

B
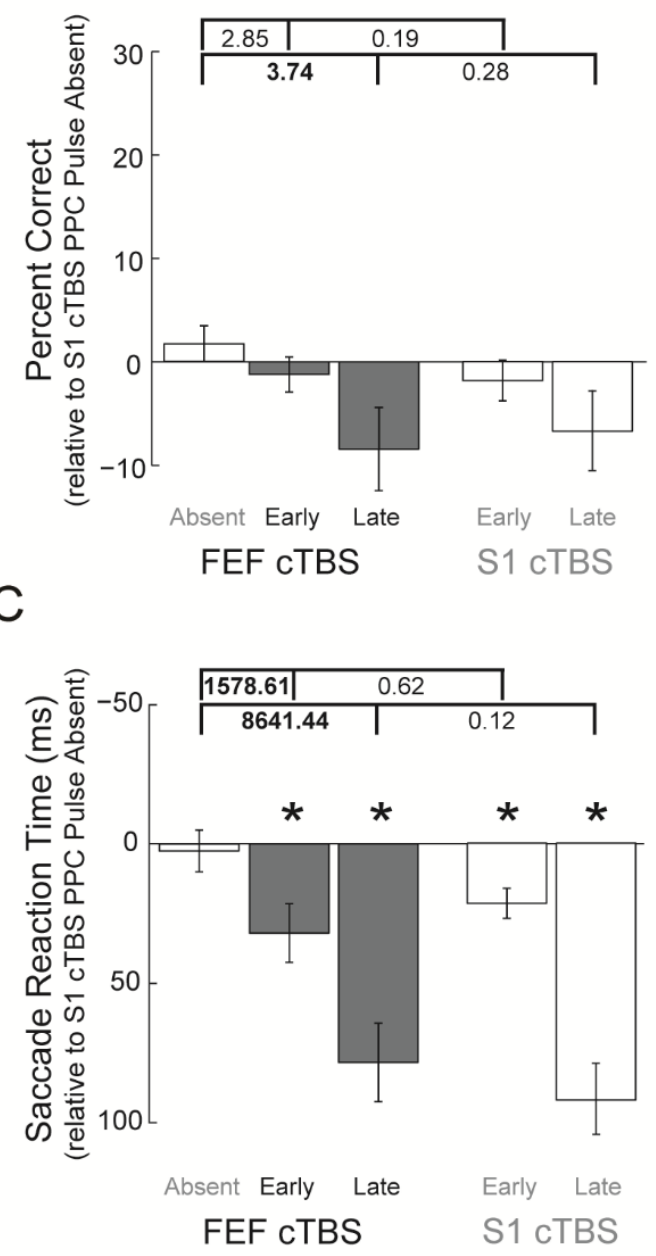

\section{Right Pro}
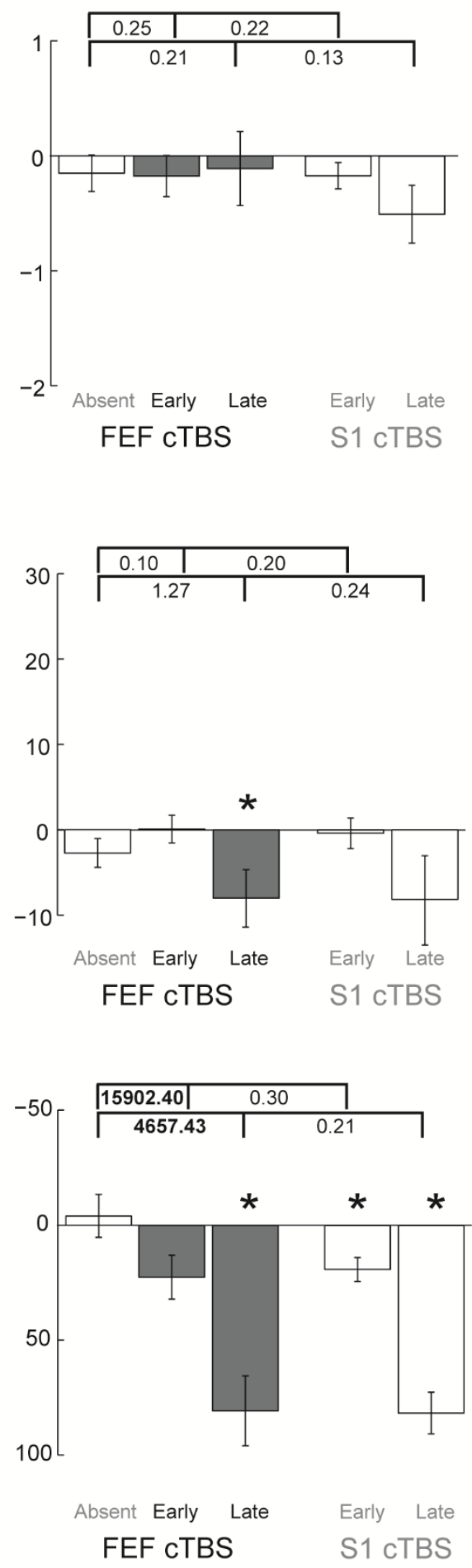

*, Bold values: $\mathrm{BF}_{10}>3$

Figure 6 
Saccade Reaction Times (SRT)

Substantial or greater evidence for pro-saccade reaction time impairments was observed for 7/8 PPC pulse conditions (Table 4C). There was also strong evidence that the combined effects of FEF cTBS and PPC pulses resulted in enhanced impairments relative to FEF cTBS alone (Figure 6C), however, there was not evidence for an enhanced impairment over the PPC pulse effects alone.

\section{Interpretation}

There was no evidence to suggest that TMS to FEF or PPC impaired pro-saccade amplitudes, suggesting that other regions in a wider network are sufficient for the spatial calculations for a pro-saccade (Munoz \& Schall, 2004). There were findings to suggest that the late PPC pulse following FEF cTBS impaired pro-saccade correct directions and substantially increased reaction times, suggesting a detrimental effect of the PPC pulse, possibly by impairing PPC-SC signals (as described previously). We acknowledge, however, that because we rejected trials when reaction time was less than the PPC pulse time, the outcome measures of the late PPC pulse are biased as coming from trials with a slower latency.

\section{DLPFC cTBS vs control cTBS conditions: pro-saccades}

\section{Saccade amplitude}

There was not substantial evidence for any effects to pro-saccade amplitudes (Table 5A, Figure 7A). 
Table 5: Bayes Factors for the alternative (impairment) vs. null (no impairment) hypothesis $\left.\underline{B F}_{10}\right)$ for left and right pro-saccade trials relative to control cTBS (The effect of the PPC pulse relative to control cTBS is shown in duplication as in Table 4)

\begin{tabular}{lccccccc}
\hline Left & cTBS & PPC & $\mathrm{BF}_{10}$ & $\begin{array}{c}\text { Right } \\
\text { Pro }\end{array}$ & $\begin{array}{c}\text { cTBS } \\
\text { site }\end{array}$ & $\begin{array}{c}\text { PPC } \\
\text { pulse }\end{array}$ & $\mathrm{BF}_{10}$ \\
Pro & site & pulse & & ren
\end{tabular}

\section{A) Amplitude}

\begin{tabular}{|c|c|c|c|c|c|}
\hline DLPFC & $\begin{array}{c}\text { Absent } \\
\text { Early } \\
\text { Late }\end{array}$ & $\begin{array}{l}0.19 \\
0.24 \\
0.15\end{array}$ & DLPFC & $\begin{array}{c}\text { Absent } \\
\text { Early } \\
\text { Late }\end{array}$ & $\begin{array}{l}0.62 \\
0.22 \\
1.03\end{array}$ \\
\hline S1 & $\begin{array}{l}\text { Early } \\
\text { Late }\end{array}$ & $\begin{array}{l}0.11 \\
0.30\end{array}$ & S1 & $\begin{array}{l}\text { Early } \\
\text { Late }\end{array}$ & $\begin{array}{l}1.07 \\
2.32\end{array}$ \\
\hline
\end{tabular}

\section{B) Percent Correct}

\begin{tabular}{|c|c|c|c|c|c|}
\hline \multirow{3}{*}{ DLPFC } & Absent & 0.22 & DLPFC & Absent & 0.17 \\
\hline & Early & 0.32 & & Early & 0.21 \\
\hline & Late & 0.42 & & Late & 2.84 \\
\hline \multirow[t]{2}{*}{$\mathrm{S} 1$} & Early & 0.48 & $\mathrm{~S} 1$ & Early & 0.24 \\
\hline & Late & 1.44 & & Late & 1.19 \\
\hline
\end{tabular}

\section{C) Saccade Reaction Time}

\begin{tabular}{|c|c|c|c|c|c|}
\hline DLPFC & $\begin{array}{c}\text { Absent } \\
\text { Early } \\
\text { Late }\end{array}$ & $\begin{array}{c}0.23 \\
1.86 \\
\mathbf{2 5 4 4 . 6 8}\end{array}$ & DLPFC & $\begin{array}{c}\text { Absent } \\
\text { Early } \\
\text { Late }\end{array}$ & $\begin{array}{c}0.34 \\
1.29 \\
\mathbf{1 1 7 2 0 0 0}\end{array}$ \\
\hline S1 & $\begin{array}{l}\text { Early } \\
\text { Late }\end{array}$ & $\begin{array}{c}55.31 \\
26318.61\end{array}$ & S1 & $\begin{array}{l}\text { Early } \\
\text { Late }\end{array}$ & $\begin{array}{c}25.74 \\
1082000\end{array}$ \\
\hline
\end{tabular}

Bold values: $\mathrm{BF}_{10}>3$

Figure 7: Effects on left and right pro-saccades when the double lesion involving DLPFC cTBS and PPC TMS is compared to the single lesion conditions. Conventions as in Figure 4. 

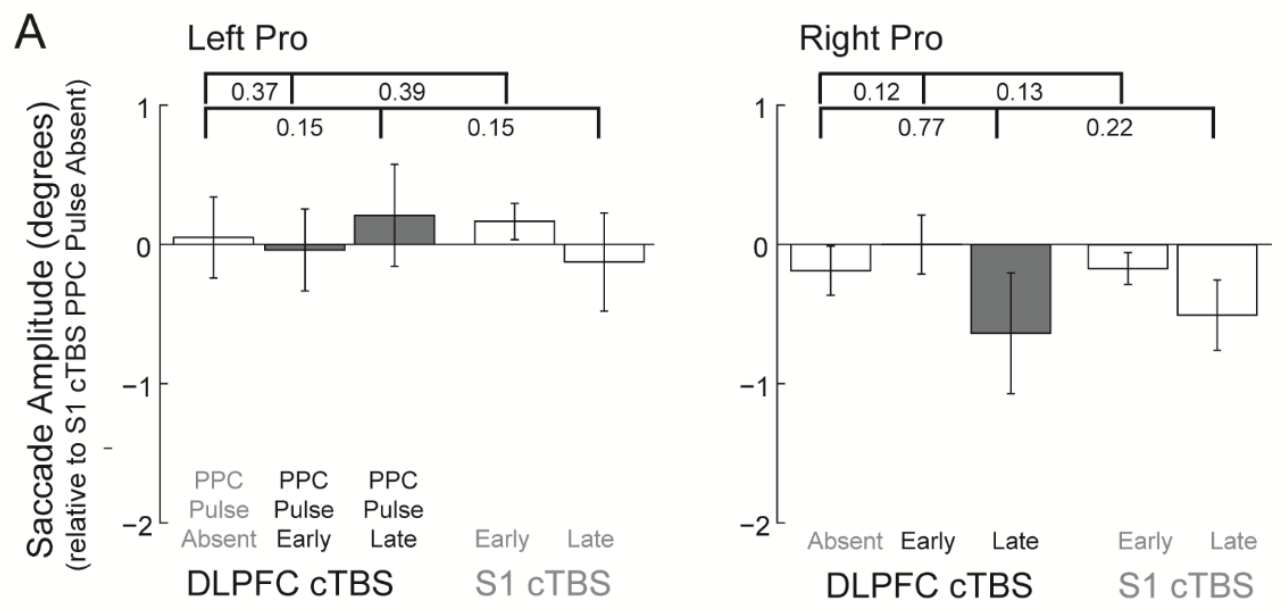

B

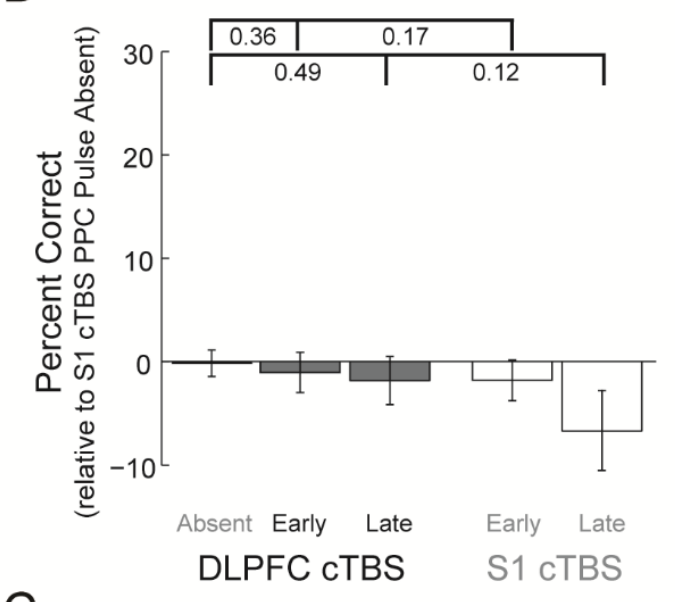

C
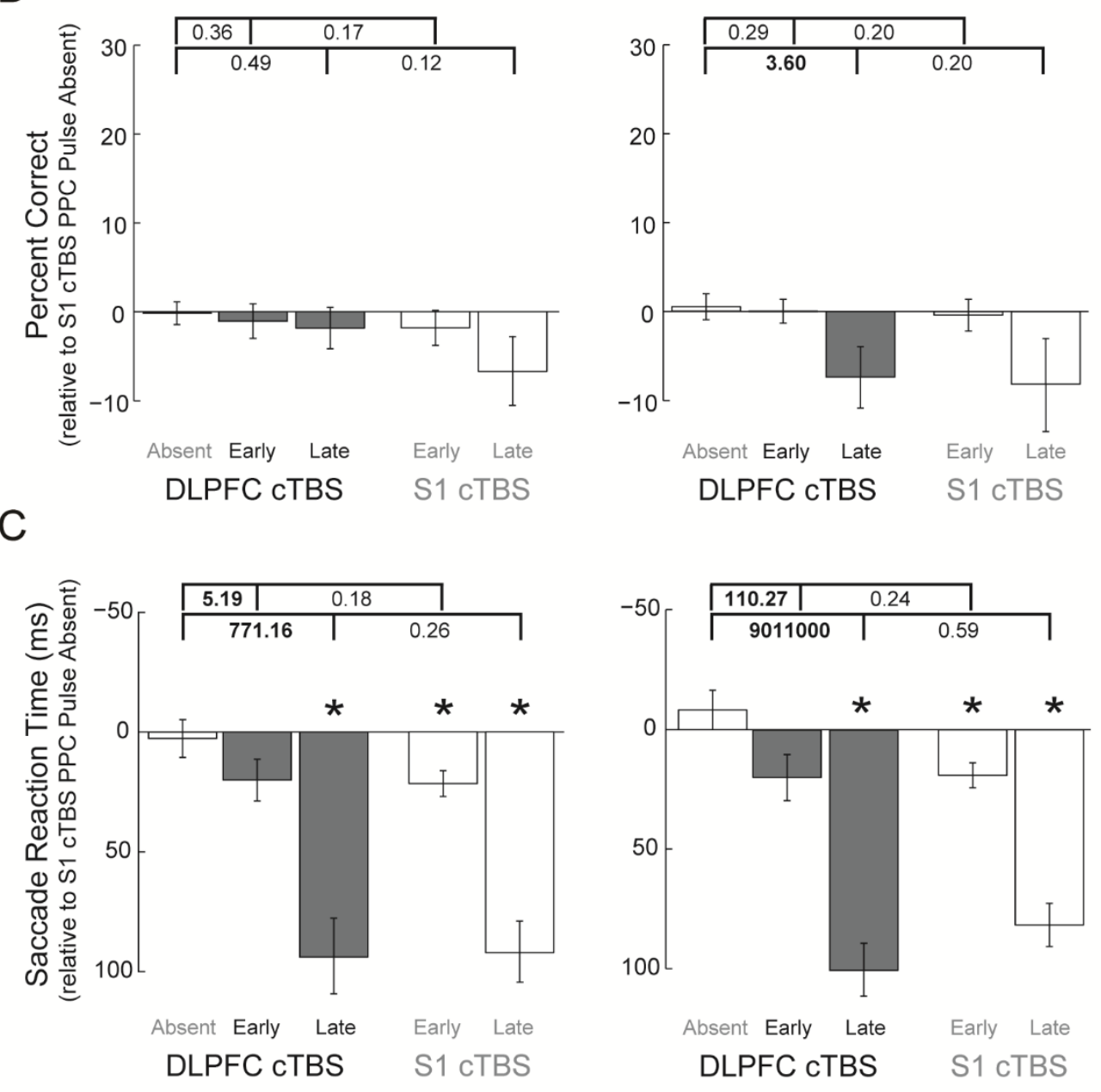

*, Bold values: $\mathrm{BF}_{10}>3$

Figure 7 


\section{Percentage correct direction}

There was substantial evidence that the impairments to rightwards pro-saccades were greater following DLPFC cTBS when the late PPC pulse was present (Figure 7B; $\mathrm{BF}_{10}=3.60$ ), but no other evidence for impairments was substantial (Table 5B).

Saccade Reaction Times (SRT)

There was decisive evidence for reaction time impairments at the late PPC pulse time following DLPFC cTBS (Table 5C). Also, there was substantial evidence that the combined effects of DLPFC cTBS and PPC pulses resulted in enhanced impairments relative to DLPFC cTBS alone (Figure 7C).

\section{Interpretation}

As with FEF cTBS, DLPFC appears not to be critical to pro-saccade amplitudes. Interestingly, the late PPC pulse following DLPFC cTBS impaired rightward pro-saccade performance compared to DLPFC cTBS alone, but it is difficult to interpret this as compensatory as this condition did not actually produce substantial evidence for an impairment $(\mathrm{BF} 10<3$, Table 5).

\section{Conclusions}

Our findings for a general lack of additive effects from two TMS lesions to critical nodes in anti-saccade programming suggest that these saccade behaviors are governed by distributed computations. A cTBS lesion to FEF, or DLPFC, may be interpreted as being consequential for the communication of information in a cortical network critical to mapping the spatial positions for an anti-saccades (Bullmore \& Sporns, 2009; Sporns, Honey, \& Kötter, 2007). The present study suggests DLPFC may be part of this network previously more emphasized to involve FEF and PPC (Medendorp et al., 2005; Moon et al., 2007; Munoz \& Everling, 2004). Importantly, 
these three nodes have been shown to be part of interconnected frontoparietal networks which are recruited when attentional control is needed (Dosenbach, Fair, Cohen, Schlaggar, \& Petersen, 2008; Ptak, 2012; Thiebaut de Schotten et al., 2011; Tschentscher, Mitchell, \& Duncan, 2017; Vossel et al., 2014). Taken together, the evidence suggests that network interactions are important, over and above summated contributions of individual nodes. 


\section{References}

Balslev, D., Albert, N. B., \& Miall, C. (2011). Eye muscle proprioception is represented bilaterally in the sensorimotor cortex. Human Brain Mapping, 32, 624-631. https://doi.org/10.1002/hbm.21050

Bullmore, E., \& Sporns, O. (2009). Complex brain networks: graph theoretical analysis of structural and functional systems. Nat Rev Neurosci, 10(3), 186-198. https://doi.org/10.1038/nrn2575

Cameron, I. G. M., Riddle, J. M., \& D’Esposito, M. (2015). Dissociable Roles of Dorsolateral Prefrontal Cortex and Frontal Eye Fields During Saccadic Eye Movements. Frontiers in Human Neuroscience, 9. https://doi.org/10.3389/fnhum.2015.00613

Chen, M., Liu, Y., Wei, L., \& Zhang, M. (2013). Parietal Cortical Neuronal Activity Is Selective for Express Saccades. Journal of Neuroscience, 33(2), 814-823. https://doi.org/10.1523/JNEUROSCI.2675-12.2013

Connolly, J. D., Goodale, M. A., Menon, R. S., \& Munoz, D. P. (2002). Human fMRI evidence for the neural correlates of preparatory set. Nature Neuroscience, 5, 1345-1352. https://doi.org/10.1038/nn969

Corbetta, M., Kincade, M. J., Lewis, C., Snyder, A. Z., \& Sapir, A. (2005). Neural basis and recovery of spatial attention deficits in spatial neglect. Nature Neuroscience, 8(11), 160310. https://doi.org/10.1038/nn1574

DeSouza, J. F. X., Menon, R. S., \& Everling, S. (2003). Preparatory set associated with prosaccades and anti-saccades in humans investigated with event-related FMRI. Journal of Neurophysiology, 89, 1016-1023. https://doi.org/10.1167/2.7.578

Dosenbach, N. U. F., Fair, D. A., Cohen, A. L., Schlaggar, B. L., \& Petersen, S. E. (2008). A dual-networks architecture of top-down control. Trends in Cognitive Sciences, 12(3), 99105. https://doi.org/10.1016/j.tics.2008.01.001

Duecker, F., de Graaf, T. A., Jacobs, C., \& Sack, A. T. (2013). Time- and Task-Dependent NonNeural Effects of Real and Sham TMS. PLOS ONE, 8(9). https://doi.org/10.1371/journal.pone.0073813

Duecker, F., \& Sack, A. T. (2013). Pre-Stimulus Sham TMS Facilitates Target Detection. PLoS ONE, 8(3). https://doi.org/10.1371/journal.pone.0057765

Everling, S., \& DeSouza, J. F. X. (2005). Rule-dependent activity for prosaccades and antisaccades in the primate prefrontal cortex. Journal of Cognitive Neuroscience, 17(9), 1483-96. https://doi.org/10.1162/0898929054985455

Everling, S., \& Johnston, K. (2013). Control of the superior colliculus by the lateral prefrontal cortex. Philosophical Transactions of the Royal Society of London. Series B, Biological Sciences, 368, 20130068. https://doi.org/10.1098/rstb.2013.0068

Hallett, P. E. (1978). Primary and secondary saccades to goals defined by instructions. Vision 
Research, 18, 1279-1296. https://doi.org/10.1016/0042-6989(78)90218-3

Hamm, J. P., Dyckman, K. A., Ethridge, L. E., McDowell, J. E., \& Clementz, B. A. (2010). Preparatory Activations across a Distributed Cortical Network Determine Production of Express Saccades in Humans. Journal of Neuroscience, 30(21), 7350-7357. https://doi.org/10.1523/JNEUROSCI.0785-10.2010

Hartwigsen, G., Saur, D., Price, C. J., Ulmer, S., Baumgaertner, A., \& Siebner, H. R. (2013). Perturbation of the left inferior frontal gyrus triggers adaptive plasticity in the right homologous area during speech production. Proceedings of the National Academy of Sciences of the United States of America, 110(41), 16402-7. https://doi.org/10.1073/pnas.1310190110

Hartwigsen, G., Weigel, A., Schuschan, P., Siebner, H. R., Weise, D., Classen, J., \& Saur, D. (2016). Dissociating Parieto-Frontal Networks for Phonological and Semantic Word Decisions: A Condition-and-Perturb TMS Study. Cerebral Cortex, 26(6), 2590-2601. https://doi.org/10.1093/cercor/bhv092

He, B. J., Snyder, A. Z., Vincent, J. L., Epstein, A., Shulman, G. L., \& Corbetta, M. (2007). Breakdown of functional connectivity in frontoparietal networks underlies behavioral deficits in spatial neglect. Neuron, 53(6), 905-18. https://doi.org/10.1016/j.neuron.2007.02.013

Huang, Y.-Z., Edwards, M. J., Rounis, E., Bhatia, K. P., \& Rothwell, J. C. (2005). Theta burst stimulation of the human motor cortex. Neuron, 45(2), 201-6. https://doi.org/10.1016/j.neuron.2004.12.033

Ilmoniemi, R. J., Virtanen, J., Ruohonen, J., Karhu, J., Aronen, H. J., Näätänen, R., \& Katila, T. (1997). Neuronal responses to magnetic stimulation reveal cortical reactivity and connectivity. NeuroReport, 8(16), 3537-3540. https://doi.org/10.1097/00001756199711100-00024

JASP Team. (2017). JASP (Version 0.8.1.1).

Jaun-Frutiger, K., Cazzoli, D., Müri, R. M., Bassetti, C. L., \& Nyffeler, T. (2013). The frontal eye field is involved in visual vector inversion in humans--a theta burst stimulation study. PloS One, 8(12), e83297. https://doi.org/10.1371/journal.pone.0083297

Jeffreys, H. (1961). Theory of Probability. Theory of Probability (Vol. 2). Retrieved from http://ocw.mit.edu/OcwWeb/Mathematics/18-175Spring-2007/LectureNotes/Index.htm

Johnston, K., \& Everling, S. (2011). Frontal cortex and flexible control of saccades. In S. P. Liversedge, I. D. Gilchrist, \& S. Everling (Eds.), The Oxford handbook of eye movements (pp. 279-302). Oxford University Press.

Johnston, K., Koval, M. J., Lomber, S. G., \& Everling, S. (2014). Macaque Dorsolateral Prefrontal Cortex Does not Suppress Saccade-Related Activity in the Superior Colliculus. Cerebral Cortex (New York, N.Y. : 1991), 24, 1373-88.

https://doi.org/10.1093/cercor/bhs424 
Ko, J. H., Monchi, O., Ptito, A., Bloomfield, P., Houle, S., \& Strafella, A. P. (2008). Theta burst stimulation-induced inhibition of dorsolateral prefrontal cortex reveals hemispheric asymmetry in striatal dopamine release during a set-shifting task: a TMS-[(11)C]raclopride PET study. The European Journal of Neuroscience, 28(10), 2147-55. https://doi.org/10.1111/j.1460-9568.2008.06501.x

Leigh, R. J., \& Kennard, C. (2004). Using saccades as a research tool in the clinical neurosciences. Brain. https://doi.org/10.1093/brain/awh035

Mackey, W. E., Devinsky, O., Doyle, W. K., Meager, M. R., \& Curtis, C. E. (2016). Human Dorsolateral Prefrontal Cortex Is Not Necessary for Spatial Working Memory. Journal of Neuroscience, 36(10), 2847-2856. https://doi.org/10.1523/JNEUROSCI.3618-15.2016

Medendorp, W. P., Goltz, H. C., \& Vilis, T. (2005). Remapping the remembered target location for anti-saccades in human posterior parietal cortex. Journal of Neurophysiology, 94(1), 734-40. https://doi.org/10.1152/jn.01331.2004

Moon, S. Y., Barton, J. J. S., Mikulski, S., Polli, F. E., Cain, M. S., Vangel, M., ... Manoach, D. S. (2007). Where left becomes right: a magnetoencephalographic study of sensorimotor transformation for antisaccades. NeuroImage, 36(4), 1313-23. https://doi.org/10.1016/j.neuroimage.2007.04.040

Morishima, Y., Akaishi, R., Yamada, Y., Okuda, J., Toma, K., \& Sakai, K. (2009). Task-specific signal transmission from prefrontal cortex in visual selective attention. Nat Neurosci, 12(1), 85-91. https://doi.org/10.1038/nn.2237

Müller-Dahlhaus, F., \& Ziemann, U. (2015). Metaplasticity in Human Cortex. The Neuroscientist : A Review Journal Bringing Neurobiology, Neurology and Psychiatry, 21(2), 185-202. https://doi.org/10.1177/1073858414526645

Munoz, D. P., Armstrong, I., \& Coe, B. (2007). Using eye movements to probe development and dysfunction. In Eye Movements (pp. 99-124). Elsevier. https://doi.org/10.1016/B978008044980-7/50007-0

Munoz, D. P., \& Everling, S. (2004). Look away: the anti-saccade task and the voluntary control of eye movement. Nature Reviews. Neuroscience, 5(3), 218-28. https://doi.org/10.1038/nrn1345

Munoz, D. P., \& Schall, J. D. (2004). Concurrent, distributed control of saccade intitiation in the Frontal Eye Field and Superior Colliculus. In W. C. Hall \& A. Moschovakis (Eds.), The superior colliculus: new approaches for studying sensorimotor integration (pp. 55-82). Boca Raton: CRC Press.

Nagel, M., Sprenger, A., Lencer, R., Kömpf, D., Siebner, H., \& Heide, W. (2008). Distributed representations of the "preparatory set" in the frontal oculomotor system: a TMS study. BMC Neuroscience, 9, 89. https://doi.org/10.1186/1471-2202-9-89

Neggers, S. F. W., van Diepen, R. M., Zandbelt, B. B., Vink, M., Mandl, R. C. W., \& Gutteling, T. P. (2012). A functional and structural investigation of the human fronto-basal volitional 
saccade network. PLoS ONE, 7. https://doi.org/10.1371/journal.pone.0029517

Nyffeler, T., Hartmann, M., Hess, C. W., \& Müri, R. M. (2008). Visual vector inversion during memory antisaccades--a TMS study. Progress in Brain Research, 171, 429-432. https://doi.org/S0079-6123(08)00663-8 [pii]|r10.1016/S0079-6123(08)00663-8

O’Shea, J., Johansen-Berg, H., Trief, D., Göbel, S., \& Rushworth, M. F. S. (2007). Functionally specific reorganization in human premotor cortex. Neuron, 54, 479-490. https://doi.org/10.1016/j.neuron.2007.04.021

Oberman, L., Edwards, D., Eldaief, M., \& Pascual-Leone, A. (2011). Safety of theta burst transcranial magnetic stimulation: a systematic review of the literature. Journal of Clinical Neurophysiology: Official Publication of the American Electroencephalographic Society, 28, 67-74. https://doi.org/10.1097/WNP.0b013e318205135f

Paré, M., \& Dorris, M. C. (2011). The role of posterior parietal cortex in the regulation of saccadic eye movements. In S. Liversedge, I. Gilchrist, \& S. Everling (Eds.), The Oxford handbook of eye movements (pp. 257-278). Oxford University Press.

Paus, T., Jech, R., Thompson, C. J., Comeau, R., Peters, T., \& Evans, a C. (1997). Transcranial magnetic stimulation during positron emission tomography: a new method for studying connectivity of the human cerebral cortex. The Journal of Neuroscience : The Official Journal of the Society for Neuroscience, 17(9), 3178-3184.

Pierrot-Deseilligny, C., Müri, R. M., Ploner, C. J., Gaymard, B., Demeret, S., \& RivaudPechoux, S. (2003). Decisional role of the dorsolateral prefrontal cortex in ocular motor behaviour. Brain, 126, 1460-1473. https://doi.org/10.1093/brain/awg148

Price, C. J., \& Friston, K. J. (2002). Degeneracy and cognitive anatomy. Trends in Cognitive Sciences, 6(10), 416-421. https://doi.org/10.1016/S1364-6613(02)01976-9

Price, C. J., Hope, T. M., \& Seghier, M. L. (2017). Ten problems and solutions when predicting individual outcome from lesion site after stroke. NeuroImage, 145, 200-208. https://doi.org/10.1016/j.neuroimage.2016.08.006

Ptak, R. (2012). The frontoparietal attention network of the human brain: action, saliency, and a priority map of the environment. The Neuroscientist : A Review Journal Bringing Neurobiology, Neurology and Psychiatry, 18(5), 502-15. https://doi.org/10.1177/1073858411409051

Rossi, S., Hallett, M., Rossini, P. M., \& Pascual-Leone, A. (2009). Safety, ethical considerations, and application guidelines for the use of transcranial magnetic stimulation in clinical practice and research. Clinical Neurophysiology: Official Journal of the International Federation of Clinical Neurophysiology, 120(12), 2008-39. https://doi.org/10.1016/j.clinph.2009.08.016

Ruff, C. C., Blankenburg, F., Bjoertomt, O., Bestmann, S., Freeman, E., Haynes, J. D., ... Driver, J. (2006). Concurrent TMS-fMRI and Psychophysics Reveal Frontal Influences on Human Retinotopic Visual Cortex. Current Biology, 16(15), 1479-1488. 
https://doi.org/10.1016/j.cub.2006.06.057

Sack, a T., Camprodon, J. a, Pascual-Leone, A., \& Goebel, R. (2005). The dynamics of interhemispheric compensatory processes in mental imagery. Science (New York, N.Y.), 308(5722), 702-4. https://doi.org/10.1126/science.1107784

Sporns, O., Honey, C. J., \& Kötter, R. (2007). Identification and classification of hubs in brain networks. PLoS ONE, 2(10). https://doi.org/10.1371/journal.pone.0001049

Thiebaut de Schotten, M., Dell'Acqua, F., Forkel, S. J., Simmons, A., Vergani, F., Murphy, D. G., \& Catani, M. (2011). A lateralized brain network for visuospatial attention. Nat Neurosci, 14(10), 1245-1246. https://doi.org/10.1038/nn.2905

Tschentscher, N., Mitchell, D., \& Duncan, J. (2017). Fluid Intelligence Predicts Novel Rule Implementation in a Distributed Frontoparietal Control Network. The Journal of Neuroscience, 37(18), 4841-4847. https://doi.org/10.1523/JNEUROSCI.2478-16.2017

Vossel, S., Geng, J. J., \& Fink, G. R. (2014). Dorsal and ventral attention systems: Distinct neural circuits but collaborative roles. Neuroscientist, 20(2), 150-159. https://doi.org/10.1177/1073858413494269

Watanabe, M., Hirai, M., Marino, R. A., \& Cameron, I. G. M. (2010). Occipital-parietal network prepares reflexive saccades. The Journal of Neuroscience: The Official Journal of the Society for Neuroscience, 30, 13917-13918. https://doi.org/10.1523/JNEUROSCI.388410.2010

Wetzels, R., Matzke, D., Lee, M. D., Rouder, J. N., Iverson, G. J., \& Wagenmakers, E. J. (2011). Statistical evidence in experimental psychology: An empirical comparison using $855 \mathrm{t}$ tests. Perspectives on Psychological Science, 6(3), 291-298. https://doi.org/10.1177/1745691611406923

Wischnewski, M., \& Schutter, D. J. L. G. (2015). Efficacy and time course of theta burst stimulation in healthy humans. Brain Stimulation. https://doi.org/10.1016/j.brs.2015.03.004

Xu-Wilson, M., Tian, J., Shadmehr, R., \& Zee, D. S. (2011). TMS perturbs saccade trajectories and unmasks an internal feedback controller for saccades. The Journal of Neuroscience : The Official Journal of the Society for Neuroscience, 31, 11537-11546. https://doi.org/10.1523/JNEUROSCI.1584-11.2011

Zhang, M., Wang, X., \& Goldberg, M. E. (2008). Monkey primary somatosensory cortex has a proprioceptive representation of eye position. Progress in Brain Research, 171, 37-45. https://doi.org/10.1016/S0079-6123(08)00606-7 